\title{
Polycythemia Vera Presenting as Hemorrhagic Stroke
}

\author{
Krishnan Balagopal ${ }^{1} \quad$ Aju Mathew ${ }^{2} \quad$ Ansa Grace Koshy ${ }^{1} \quad$ Jerin Peter Jacob ${ }^{1}$ \\ ${ }^{1}$ Department of Neurology, MOSC Medical College, Kolenchery, \\ Kochi, Kerala, India \\ ${ }^{2}$ Department of Hemato-Oncology, MOSC Medical College, \\ Kolenchery, Kochi, Kerala, India

\begin{abstract}
Address for correspondence Krishnan Balagopal, DM, Department of Neurology, MOSC Medical College, Medical College Road, PO kolencherrym, Kochi, Kerala 682311, India (e-mail: krishnan.balagopal@gmail.com).
\end{abstract}

J Neurosci Rural Pract 2021;12:601-602.

\begin{abstract}
Keywords

- polycythemia vera

- hemorrhagic stroke

- hypercoagulable state

Patients with polycythemia vera are at high risk for vaso-occlusive events including cerebral ischemia and hemorrhage. Cerebral ischemic events are due to increased blood viscosity and platelet activation within the central nervous system arterial vessels. We present a case of a 65 -year-old woman who presented to the emergency department with seizures followed by left-sided weakness. Hematologic investigations revealed a hyperviscous state, and magnetic resonance imaging (MRI) was consistent with bilateral hemorrhagic infarction. Genetic studies were positive for polycythemia vera mutation. Symptoms improved with phlebotomy and antiplatelet agents. Through this case, we aim to highlight polycythemia vera as a cause of hemorrhagic stroke and the importance of blood counts in the routine evaluation of the same.
\end{abstract}

\section{Introduction}

Polycythemia vera (PV) is a myeloproliferative disease characterized by clonal proliferation of hematopoietic stem cells, leading to abnormal increases in circulating red blood cells, white blood cells, and platelets, resulting in an increase in blood viscosity and reduction in blood flow velocity. ${ }^{1}$ These disorders of hemorheology are contributing factors for thrombosis, resulting in cerebral infarction. In some situations, the condition is associated with cerebral hemorrhage due to dysfunction in platelet aggregation and the prolongation of activated partial prothrombin time. ${ }^{2,3}$ Stroke may be the first presenting symptom of PV in $15 \%$ or more of those affected by the disease. ${ }^{4}$ Here, we present a case of a 65-year-old patient who presented with bilateral hemorrhagic infarcts.

\section{Case Report}

A 65-year-old woman with a history of diabetes and hypertension presented to the emergency department with an episode of generalized seizures, followed by weakness of left upper and lower extremities and altered sensorium. On examination, the patient was noted to be in the postictal state with left hemiparesis. Her blood pressure was 180/100 $\mathrm{mm} \mathrm{Hg}$. Imaging studies showed areas of infarction in bilateral parieto-occipital, right thalamic, right basal ganglia, and frontal white matter (-Figs 1-5). Hemorrhagic transformation was seen in bilateral parieto-occipital regions. Magnetic resonance angiography (MRA) of the brain showed hypoplastic right vertebral artery. On laboratory evaluation, she was noted to have a hemoglobin level of $16.1 \mathrm{~g} / \mathrm{dL}$ associated with elevated total white blood count of $49,390 / \mathrm{mm}^{3}$ and platelet count of 8.35 lakhs $/ \mathrm{mm}^{3}$. We considered the possibility of a myeloproliferative neoplasm. Genetic work-up revealed a JAK2 V617F mutation, which is characteristically seen in patients with PV. She was started on antiplatelet agents. We also performed therapeutic phlebotomy to reduce the hemoglobin to a goal of less than $14.5 \mathrm{~g} / \mathrm{dL}$. Subsequently, both her sensorium and motor power improved with physiotherapy. To keep her platelet count to a goal of less than 5 lakhs $/ \mathrm{mm}^{3}$, we also started her on hydroxyurea.

\section{published online}

May 5, 2021
DOI https://doi.org/

$10.1055 / \mathrm{s}-0041-1729478$ ISSN 0976-3147
(C) 2021. Association for Helping Neurosurgical Sick People.

This is an open access article published by Thieme under the terms of the Creative Commons Attribution-NonDerivative-NonCommercial-License, permitting copying and reproduction so long as the original work is given appropriate credit. Contents may not be used for commercial purposes, or adapted, remixed, transformed or built upon. (https://creativecommons.org/licenses/by-nc-nd/4.0/).

Thieme Medical and Scientific Publishers Pvt. Ltd. A-12, 2nd Floor, Sector 2, Noida-201301 UP, India 


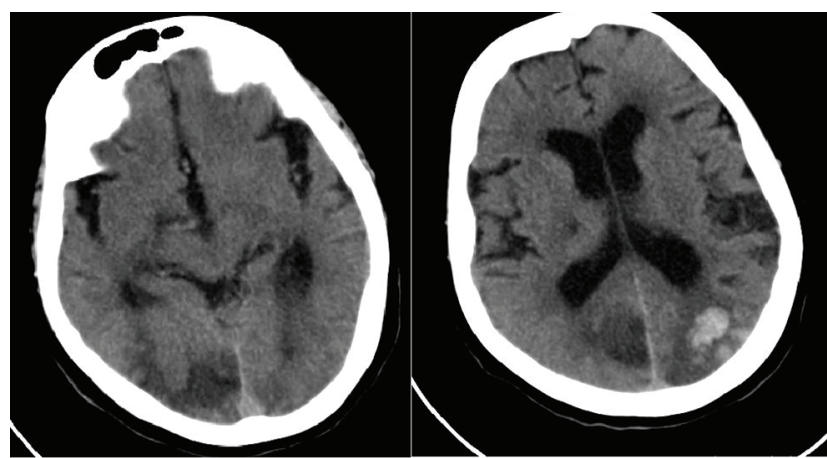

Fig. $1 \mathrm{CT}$ brain showing bilateral hemorrhagic infarction in the parieto-occipital lobes.
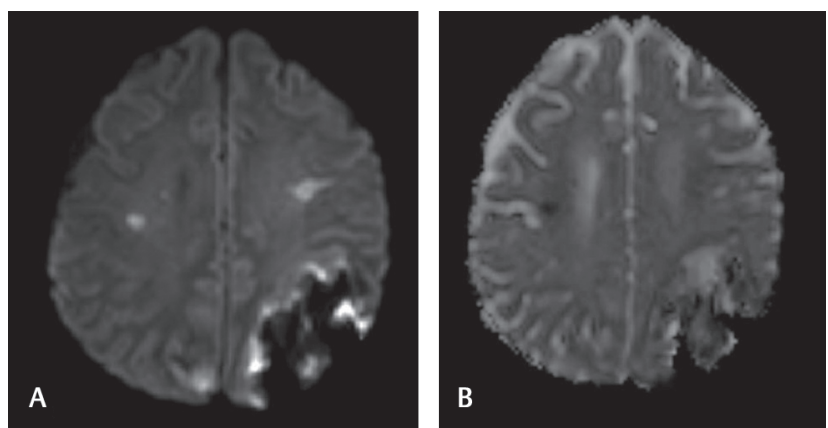

Fig. 3 (A) Diffusion-weighted imaging and (B) apparent diffusion coefficient images showing bilateral frontal and occipital infarcts.
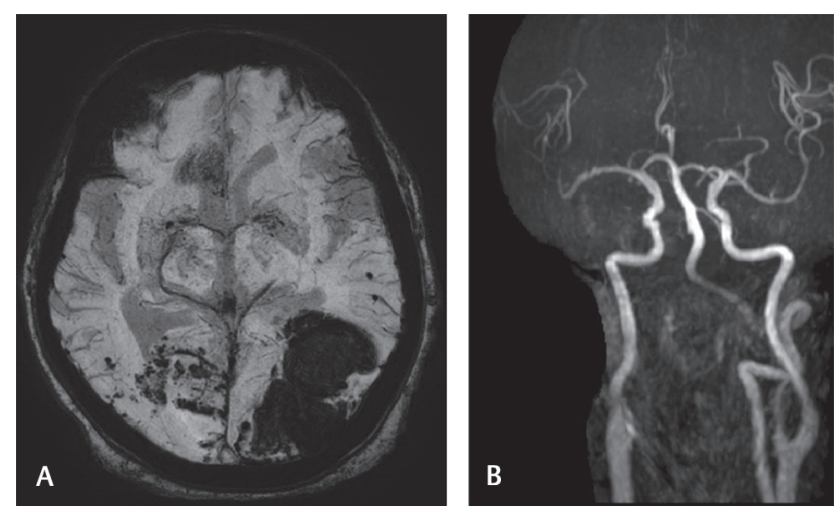

Fig. 5 (A) Susceptibility-weighted imaging (SWI) images showing hemorrhagic areas in both parieto-occipital lobes. (B) Magnetic resonance angiography (MRA) showing hypoplastic right vertebral artery on MRA.

\section{Discussion}

$\mathrm{PV}$ is a rare cause of both cerebral thrombosis and hemorrhage. The etiology of PV is attributed to a gain of function mutation of the JAK2 domain (Janus Activated Kinase (JAK)2 V617F mutation) found in more than $95 \%$ of patients. ${ }^{5}$ Chemotherapy with hydroxyurea and anagrelide, a medication that inhibits the maturation of platelets, may also be used in conjunction with phlebotomy and antiplatelet agents. ${ }^{6} \mathrm{PV}$ should be considered in the differential diagnosis of stroke in multiple territories. It is imperative to pay close attention to routine blood investigation, which in this case turned out to be anything but routine.

\section{Funding}

None.
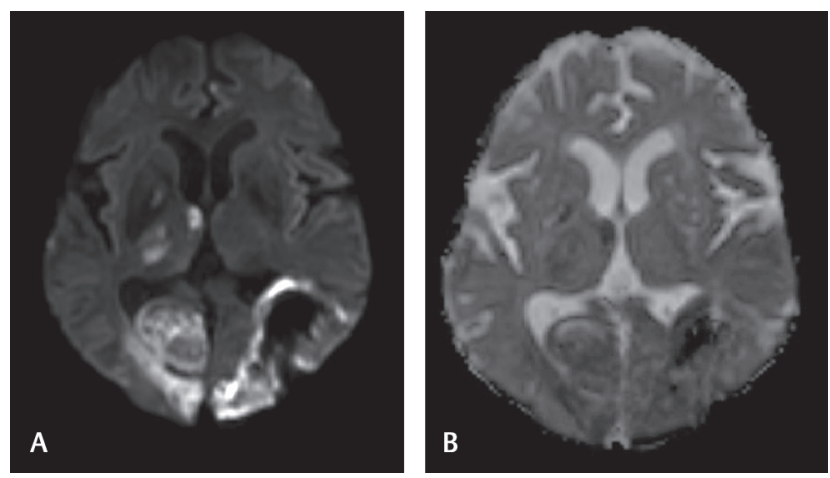

Fig. 2 (A) Diffusion-weighted imaging (DWI) and (B) apparent diffusion coefficient (ADC) images showing areas of restricted diffusion on DWI involving right thalamus, bilateral parieto-occipital lobes, and corresponding areas on ADC.

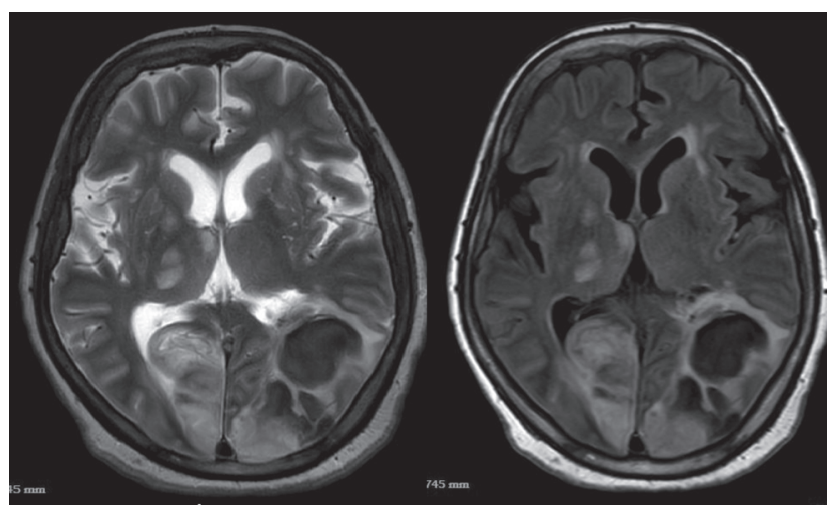

Fig. 4 T2/FLAIR (fluid-attenuated inversion recovery) images showing bilateral hemorrhagic infarcts involving parieto-occipital lobes.

\section{Conflict of interest \\ None declared.}

\section{Acknowledgments}

The authors wish to thank their friends and family for their support.

\section{References}

1 Spivak JL. Polycythemia vera. Curr Treat Options Oncol 2018;19(2):12

2 Lim Y, Lee JO, Kim SH, et al. Prediction of thrombotic and hemorrhagic events during polycythemia vera or essential thrombocythemia based on leukocyte burden. Thromb Res 2015;135(5):846-851

3 Marchioli R, Finazzi G, Specchia G, et al; CYTO-PV Collaborative Group. Cardiovascular events and intensity of treatment in polycythemia vera. N Engl J Med 2013;368(1):22-33

4 Gruppo Italiano Studio Policitemia. Polycythemia vera: the natural history of 1213 patients followed for 20 years. Ann Intern Med 1995;123(9):656-664

5 Levine RL, Wadleigh M, Cools J, et al. Activating mutation in the tyrosine kinase JAK2 in polycythemia vera, essential thrombocythemia, and myeloid metaplasia with myelofibrosis. Cancer Cell 2005;7(4):387-397

6 Landolfi R, Marchioli R, Kutti J, et al; European Collaboration on Low-Dose Aspirin in Polycythemia Vera Investigators. Efficacy and safety of low-dose aspirin in polycythemia vera. N Engl J Med 2004;350(2):114-124 